\title{
Territory quality affects female preference in a Lake Victoria cichlid fish
}

\author{
Peter D. Dijkstra • Els M. van der Zee • \\ Ton G. G. Groothuis
}

Received: 14 February 2007 /Revised: 3 September 2007 / Accepted: 4 September 2007 / Published online: 9 October 2007

(C) Springer-Verlag 2007

\begin{abstract}
Mate preferences on male colour have been implicated in generating and maintaining species diversity among haplochromine cichlid fish. Their lek-like mating system suggests that not only male colour but also territory quality is instrumental in mate choice. We assessed the relative importance of territory quality and male colour in mate choice by testing whether territory quality can override the female preference for males of her own colour in the Lake Victoria cichlid genus Pundamilia. First, we showed in experimental groups that the dominant male preferentially monopolised a large tube relative to a small tube. The situation mimics quality difference in rocky crevices that serves as a focal point for male courtship display. Second, in mate-choice tests, Pundamilia nyererei females were allowed to choose between closely related $P$. nyererei and $P$. pundamilia males; these species differ strikingly in male nuptial coloration, but little else. We gave either both males the same small tube or one of them a large tube. The preference of $P$. nyererei females for $P$. nyererei males in the control situation (where both males had a small tube) was significantly diminished in favour of $P$. pundamilia males when the latter had the large tube. The results provide experimental evidence that differences in territory quality can override the female preference for males of her own colour. This finding is critical for a recent hypothesis proposing that male competition for mating territories can facilitate the process of sympatric speciation by sexual selection.
\end{abstract}

Communicated by J. Krause

P. D. Dijkstra $(\bowtie) \cdot$ E. M. van der Zee • T. G. G. Groothuis Behavioural Biology Group, University of Groningen, P.O. Box 14, 9750 AA Haren, The Netherlands e-mail: P.D.Dijkstra@rug.nl
Keywords Mate choice $\cdot$ Haplochromine cichlid . Male-male competition $\cdot$ Sexual selection

\section{Introduction}

The colourful haplochromine cichlid species flocks of the Great African Lakes has become a classic example of explosive speciation and adaptive radiation (Seehausen 2006). The astounding species diversity in Lake Victoria ( $>500$ species) probably evolved from a few ancestors in less than 15,000 years (Johnson et al. 1996; Seehausen et al. 2003; Seehausen 2006). The promiscuous mating system of haplochromines, with exclusive female parental care in the form of mouthbrooding, is conducive to strong sexual selection by female mate choice generating and maintaining genetic differentiation (Dominey 1984). Experimental evidence showed that females base their mate choice on male colour (Seehausen et al. 1997, 1999; Seehausen and Van Alphen 1999). The importance of male colour is further corroborated by the observation that many closely related sympatric species differ strikingly in male coloration but little else (Seehausen and Van Alphen 1999).

Mate choice is often based on multiple cues in wide range of taxonomic categories (e.g. Alatalo et al. 1986; see Candolin 2003 for review). In haplochromines, not only male colour but also territory quality may play a role in mate choice decisions and sexual selection. Haplochromine males establish individual territories on leks, and females visit these assemblies for egg fertilisation. Territory ownership is a prerequisite to gain access to spawnings (Parker and Kornfield 1996; Maan et al. 2004). Hence, competition over territory sites is intense and is likely to affect sexual selection (Seehausen and Schluter 2004). 
Several studies on lekking animal species have demonstrated that territory characteristics are involved in assessment of conspecific mate quality (see Höglund and Alatalo 1995 for a review). For example, males of several sand-dwelling Lake Malawi cichlids construct and defend sand structures (termed bowers) that function mainly as display sites (McKaye et al. 1990). Field studies indicate that bower shape and size (McKaye et al. 1990; Taylor et al. 1998; Kellog et al. 2000) as well as central bower position within the lek (McKaye 1991) are correlated with male mating success. Some of these authors (Taylor et al. 1998) suggest these display sites are ornaments indicating the physical or genetic quality of the male (Zahavi 1975).

Historically, attention has focused on how multiple cues can reinforce one another and how they can jointly facilitate diversification of sexually selected traits among closely related taxonomic groups (reviewed in Andersson 1994). Yet, when cues for high-quality conspecific mates (for example large body size) resemble characteristics of heterospecifics, mate quality cues may oppose speciesrecognition cues (Pfennig 1998; Hankison and Morris 2003; Wymann and Whiting 2003). In the swordtail fish Xiphophorus pygmaeus, females have a preference for larger males, which may lead to a preference for the larger heterospecific X. cortezi males (Hankison and Morris 2003). Only in the presence of two species-specific cues (vertical bars and chemical cues) females preferred the smaller conspecific males. In haplochromines, females may face a conflict between territory quality and preference for own species when heterospecifics are stronger competitors and occupy better-quality territories. To our knowledge, there is no experimental study in which the conflict between mate quality and species-recognition cues was imposed by territory quality. Evidence for such a conflict is also relevant for our understanding of how novel colour types can invade a population, contributing to the process of sympatric speciation (Seehausen and Schluter 2004).

We tested whether female preference for males with high territory quality can override the preference for males of her own colour. Pundamilia nyererei (Witte-Maas and Witte 1985) and P. pundamilia (Seehausen et al. 1998), rockdwelling sibling cichlid species, occur sympatrically at many locations in Lake Victoria. They exhibit a common colour polymorphism in haplochromines (Seehausen 1996, 1997; Smith and Kornfield 2002). Females are cryptically coloured. Males of $P$. nyererei are bright red with yellow flanks, and P. pundamilia males are metallic blue. For convenience, we will refer to $P$. nyererei as 'red' and to $P$. pundamilia as 'blue'. Off the coast of Kissenda Island, red and blue mainly occur as distinct phenotypes, with occasional intermediate phenotypes, indicating some hybridisation. Red and blue from Kissenda Island are genetically very similar species (Seehausen unpublished), making it a suitable system to measure mate choice based on colour. Females of both species prefer conspecific males in mate-choice experiments when colour differences are visible, but not when they are masked (Seehausen and Van Alphen 1998). Pundamilia males establish individual territories over rocky and sandy bottoms, often with a rocky crevice as the focal point of their territory. Males compete for territories that vary in size, number and shape of rocks and interstitial crevices and number of neighbouring territorial males (Maan et al. 2004). In a field study, mate choice of red females was positively influenced by territory size (Maan et al. 2004).

In the laboratory study described here, we tested whether territory quality affects mate choice and can override the colour preference of red females. To create a difference in territory quality, we used tubes of two sizes. The tubes mimic a rocky crevice serving as a spawning location in a male's territory. We expected that a large tube mimicking a large crevice would correspond to a relatively high-quality territory. This was based on the observation that, in the presence of large and small tubes, dominant males often occupy the large tube. To test this, we investigated dominance-hierarchy formation in relation to occupation of different sizes of tubes in groups of Pundamilia males. Next, to confirm an earlier finding that red females have a colour preference for red (conspecific) males when both males have similar territories (Seehausen and Van Alphen 1998), we allowed females in simultaneous mate-choice tests to choose between a red male and a blue male both occupying a small tube (same-tube treatment). Finally, we repeated the choice tests, but gave the blue male a large tube and the red male a small tube (blue-large-tube treatment) or vice versa (red-large-tube treatment). We predicted that the female preference for red (conspecific) males would be reduced in the blue-large-tube treatment.

\section{General methods}

Fish and general housing condition

All fish originated from the Mwanza Gulf in Lake Victoria, Tanzania. We used wild-caught individuals and first-generation laboratory-bred offspring. Laboratory breeding was carried out in single-species breeding tanks. All fish used in this study were sexually mature (standard length $>50 \mathrm{~mm}$ ).

All fish were fed with flake food (TetraMin Tropical Fish Flakes) twice a day and a mixture of ground peas and shrimp with added vitamins twice a week. All aquaria were connected to a central biological filtration system, and the water was circulated continuously. Water temperature was 
kept at $25 \pm 2^{\circ} \mathrm{C}$, and a $12: 12 \mathrm{~h}$ light/dark cycle was maintained. All aquaria contained a substrate of gravel.

\section{Experiment I: tube occupation}

In this experiment, we tested whether dominant males prefer to occupy a large over a small tube. This experiment was performed in a group context, because it allows for prolonged observations of territorial defence by dominant males. This is not possible using dyadic encounters, because after a fight, contestants have to be separated immediately (Dijkstra et al. 2005).

\section{Methods}

Fish and housing

We used 78 males of Pundamilia (24 P. nyererei [red] and 54 P. pundamilia [blue] standard length range $57-114 \mathrm{~mm}$ ) of which 56 were first generation and 22 wild caught. Before use in a test, males were housed in individual compartments with visual access to a Pundamilia male behind a transparent screen for at least 3 days. We used three test tanks (one tank of $150 \times 40 \times 50 \mathrm{~cm}$ and two of $250 \times 46 \times 66 \mathrm{~cm}, l \times w \times h)$. In each test tank, we permanently housed eight red first-generation females.

\section{Procedure}

To test our assumption that dominant males preferentially occupy the large tube, we allowed dominance-hierarchy formation among males and analysed tube occupation by the most dominant male (alpha male) in a community. We marked out three equal-sized zones with white tape on the front side of a test tank. In one end zone, we placed a large, dark grey polyvinyl chloride (PVC) tube (diameter $15 \mathrm{~cm}$, length $21 \mathrm{~cm}$ ) on the bottom in a horizontal position to create a large crevice, and in the other end zone, a small, dark grey tube (diameter $5 \mathrm{~cm}$, length $7 \mathrm{~cm}$ ) corresponding to a small crevice. We clipped each male on its dorsal and caudal fins, using scissors, for individual recognition (Dijkstra et al. 2007a). One day before testing, a group of eight Pundamilia males were allowed to acclimatise to the tank, in which eight red females were already established. All fish were confined to the central zone with opaque screens. On the test day, we removed the screens. After $1 \mathrm{~h}$, we started the behavioural observations (see below).

A group consisted of either solely red males $(N=5$ groups) or solely blue males ( $N=9$ groups). Males of both species readily courted red females. As only the alpha male was of interest (see below), 34 subdominant males were used a second time in another test with a different group composition of males, at least 3 days later.

\section{Behavioural observations}

We observed each group of fish for at least $30 \mathrm{~min}$. The males showed the common repertoire of aggressive and sexual behaviours in cichlids (Baerends and Baerends-Van Roon 1950). We recorded aggressive behaviours, consisting of either a chase, in which a male charged towards another male, or an aggressive display, in which a male erected his fins (Baerends and Baerends-Van Roon 1950). For each behaviour, we noted in which zone of the tank it took place or from which zone the behaviour was initiated in cases where the male moved between zones. In most aggressive interactions, we were able to identify the winner (the fish that chased or displayed) and the loser (the fish that was being chased or fled after display). This information was used to determine the alpha male (see below). In addition, we recorded in which zone male courtship took place, defined as lateral display, quiver, lead swim or presentation of egg-dummies (McElroy and Kornfield 1990; Seehausen 1996), but we did not distinguish between these different types of courtship display. All observations were conducted by two persons; one person acted as the observer, and the other noted all observations on a sheet.

\section{Analysis}

To determine the social position of each male in the tank, we generated dominance matrices for each group. To derive a dominance hierarchy, we calculated the average dominance index for each individual, which is the average of its relative dominance indices against all opponents with which it interacts (Hemelrijk et al. 2005). The relative dominance index against a given opponent is calculated as the number of times the individual beats that opponent divided by the total number of fights they engaged in. The fish with the highest average dominance index was defined as the most dominant male (alpha male). This was a reliable method of identifying the alpha male: In all communities, the alpha male was the brightest male (Dijkstra et al. 2007a), and there were no cases of intransitivities involving the male with the highest average dominance index.

To evaluate tube occupation by the alpha male, we compared the percentage of aggressive behaviours and courtship events in or initiated from the zone with the large tube relative to the one with the small tube using Wilcoxon signed-ranks (WSR) tests. We also evaluated the location of behaviours performed by subordinate males. We predict that subordinates have no location preference, because the location of their behaviour is dictated by the behaviour of the alpha male. The location of behaviours of the alpha 
male is therefore more informative about tube size preference than that of subordinate males.

The data in the text are presented as medians with the inter-quartile range (25th-75th percentile). All quoted probabilities are for two-tailed tests of significance.

\section{Results}

The frequency of aggressive behaviours of the alpha male was 3.0/min per tank (1.9-5.1). Alpha males initiated more attacks on other males from the zone with the large tube relative to the zone with the small tube (Fig. 1a, WSR test: $Z=-2.229, P=$ $0.026, N=14$ ). In all but one of the 14 communities, the alpha male showed courtship behaviour. The frequency of courtship displays by the alpha male was $0.08 / \mathrm{min}$ per tank (0.03-0.23). Alpha males performed significantly more courtship displays in the large-tube zone relative to the small-tube zone (Fig. 1b, WSR test: $Z=-2.313, P=0.021, N=13$ ). These results indicate that alpha males have a preference for the large tube.

The frequency of aggressive behaviours of the subordinate males was $0.19 / \mathrm{min}$ per male and tank $(0.16-0.27)$. Subordinate males did not initiated more attacks on other males from the zone with the large tube relative to the zone with the small tube (large zone: $37 \%$ [21-47\%]; small zone: $39 \%$ [24-58\%], WSR test: $Z=-0.534, P=0.59, N=14)$. In 10 out of 14 communities, one or more subordinate male(s) showed courtship behaviour. The frequency of courtship displays by the subordinate male was $0.005 / \mathrm{min}$ per male and tank (0.000-0.002). Subordinate males did not perform significantly more courtship displays in the large-tube zone relative to the small-tube zone (large zone: $50 \%$ [0-89\%]; small zone: $50 \%$ [1-75\%], WSR test: $Z=-0.140, P=0.89, N=10)$.

\section{Experiment II: mate choice}

In this experiment, we used mate-choice tests to examine whether tube size can override the female preference for conspecific males.

\section{Method}

Same-tube treatment

\section{Fish and housing condition}

The test fish were lab-bred first-generation females (standard length range 50-73 $\mathrm{mm}$ ) of $P$. nyererei, bred from 41 wildcaught fish originating from Kissenda Island (Seehausen 1996). At this location, P. nyererei (red) and P. pundamilia (blue) males defend neighbouring territories (Seehausen

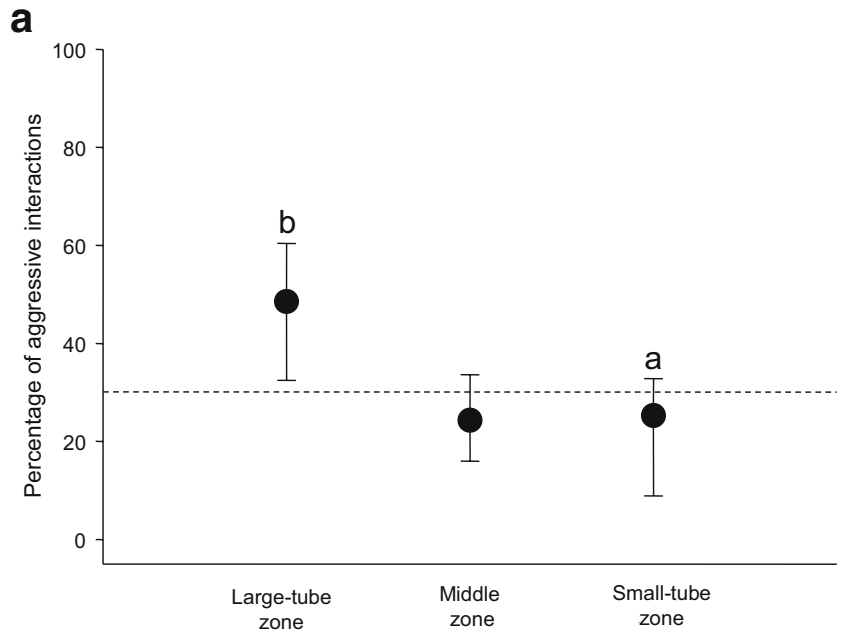

b

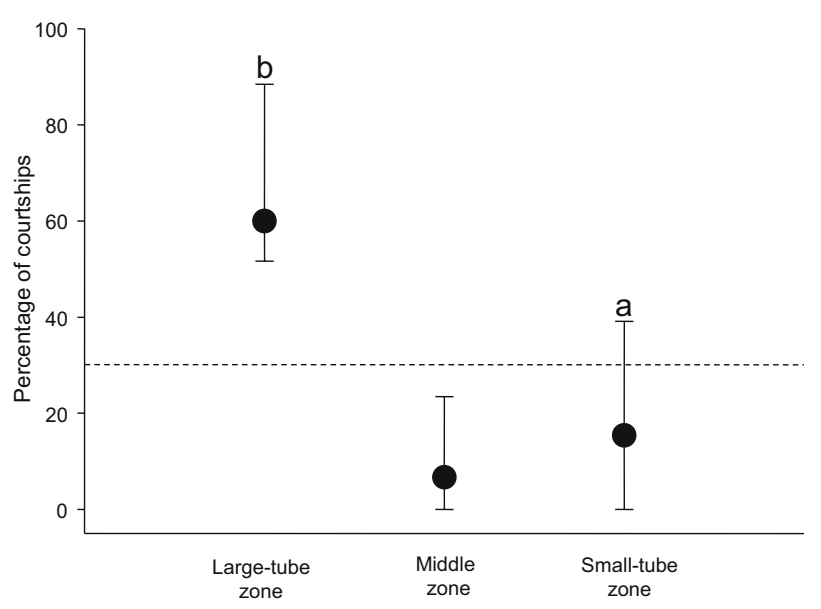

Fig. 1 a Percentage (median and inter-quartile range) of aggressive interactions $(N=1918)$ with all males initiated by the alpha male in each zone separately. The dotted line (33.33\%) indicates an equal number of aggressive interactions in all three zones. The percentage of aggressive interactions in the large-tube zone is significantly higher than that in the small-tube zone (WSR test, $N=14$ ). Data points with different letters are significantly different from each other, $P<0.05$. b Percentage (median and inter-quartile range) of courtship behaviors $(N=124)$ performed by the alpha male in each zone separately. The dotted line $(33.33 \%)$ indicates an equal number of courtship events in all three zones. The percentage of courtship behaviors in the large-tube zone is significantly higher than that in the small-tube zone (WSR test, $N=13$; one tank excluded because the alpha male did not court). Data points with different letters are significantly different from each other, $P<0.05$

1997). First-generation males and females were raised in mixed-sex, mixed-species groups. At least 4 weeks before testing, 38 females were housed in all-female tanks in groups of about ten individuals. We selected gravid females for testing. Gravidity was determined by swelling of the abdomen and urogenital opening (Seehausen and Van Alphen 1998). After testing, females were put in other all-female tanks to avoid re-use. In total, 17 red males $(77-103 \mathrm{~mm}$, of which 14 were first-generation and 3 wild-caught) and 18 
blue males (77-102 mm, of which 14 were first-generation and 4 wild-caught) were used, randomly (re)combined into 34 size-matched stimulus pairs. The same males were used as in experiment I. To use in a test, males were housed in individual compartments in the same way as in experiment I for at least a week.

Courtship in Pundamilia resembles that of other haplochromine species (McElroy and Kornfield 1990; Seehausen 1996). It typically starts with a male approaching the female, immediately followed by lateral display, in which the male positions himself perpendicular to the female and spreads all fins. This is followed by a quiver, a high-frequency shaking movement of the body. Finally, the male leads the female to the centre of the territory with exaggerated tail beats (lead swim), where he presents the egg-dummies on his anal fin. All these courtship elements can also occur in isolation of each other or in a different sequence. Mating occurs in rocky crevices, and immediately after spawning, the female leaves the territory with the eggs in her mouth (Seehausen 1996).

\section{Procedure}

To test the $P$. nyererei female preference for red (conspecific) mates, we carried out simultaneous mate-choice tests in which we allowed females to choose between a blue and a red male. The test tank $(150 \times 40 \times 50 \mathrm{~cm})$ was divided into three equal-sized compartments by a double layer of transparent Perspex screens (see below). In each of the male compartments, at either end of the tank, we placed a small, dark grey PVC tube, similar to the one used in experiment I, in a horizontal position on the bottom of the tank. As tube size was the same for both males, we refer to this as the 'same-tube treatment'.

For each trial, we placed a red male and a blue male in opposite side compartments. The left and right positions of the stimulus males with respect to colour were randomised across tests. Stimulus males were randomly matched for body length, such that the difference in length was less than $5 \%$ of the length of the shortest fish. These males were left overnight in the experimental tank. An additional red male was placed in the central compartment to maintain territoriality in both stimulus males (red evokes more territorial aggression than blue from both red and blue territorial males, see Dijkstra et al. 2006, 2007b). The next day, this central male was removed. After positioning opaque screens on either side of the central compartment, we gently put in the test female, together with a small tube for shelter. The opaque screens prevented the fish from seeing each other. The fish were then allowed to settle for $1.5 \mathrm{~h}$. At the start of the pre-test, we removed the opaque screens, leaving in place the double layer of transparent screens. One of these screens was perforated with holes of diameter $2.3 \mathrm{~cm}$, small enough for females but not males to swim through. The other screen lacked holes, and therefore, the females were initially confined to the central compartment This pre-test lasted for $5 \mathrm{~min}$, during which the females could see both the males and their territories. To begin the test, the solid screens were removed, leaving in place the perforated screens. The actual test lasted $25 \mathrm{~min}$. We videotaped the behaviour of the female and the males. From the tapes, we recorded male courtship behaviours and the frequency with which a male display was followed by a female approach (positive female response). For a reliable measure of female preference, both males should display several times to the female. Therefore, we defined a trial as successful when (1) both males courted at least four times whilst the female was visiting his compartment and (2) the female showed at least one positive response to at least one of the males (Seehausen and Van Alphen 1998). We ran a total of 14 successful trials, each with another stimulus pair combination, using 11 red and 11 blue males. When using a male for the second time, he was never paired with the same male (Kodric-Brown and Johnson 2002; Pauers et al. 2004).

\section{Red-large-tube and blue-large-tube treatment}

In this experiment, we formed stimulus pairs from the same stimulus males (17 red and 18 blue) and selected randomly gravid females from the same 38 individuals as in the sametube treatment. To test whether females prefer males with a high-quality territory and to test whether this can override colour-based female mate choice, we carried out matechoice tests with the same set-up as described above, but with the following modifications. In the male compartments, we created a difference in territory quality in the same way as in experiment I: One male was given a small tube and the other male a large tube. Females were exposed to two treatments: one in which the red male occupied the large tube and the blue male the small tube (referred to as 'red-large-tube treatment'), and one in which the blue male received the large tube and the red male the small tube (referred to as 'blue-large-tube treatment'). We ran a total of 14 successful trials in each treatment. Some females acted in both treatments to minimise inter-female variation between treatments. Between use in the different treatments, females were housed in all-female tanks and were left for at least 1 day. Although individual identity of the females was unknown, we ensured that the same female could act no more than once in each of the two treatments. In each treatment, we tested females with another stimulus pair combination, using 11 red and 12 blue males in the redlarge-tube treatment, and 9 red and 9 blue males in the bluelarge-tube treatment. When using a male for the second time, he was never paired with the same male (Kodric-Brown and Johnson 2002; Pauers et al. 2004). 


\section{Analysis}

During the pre-test, in which females were able to see both the males and their territories for $5 \mathrm{~min}$, the red and blue males did not differ in courtship frequency (WSR tests: $Z \mathrm{~s}>-1.475, P \mathrm{~s}>$ $0.14, N=14$ for same-tube and both red-large-tube and bluelarge-tube treatment).

The frequency of male courtship display was calculated as the number of displays relative to the time the female spent in his compartment. The proportion of male courtship displays resulting in the approach of a female, relative to the total number of displays, is our measure of mate choice. It controls for possible differences in display behaviour between males. We refer to this measure of mate choice as the proportion of positive female responses. This measure corresponds well with spawning decisions, and thus actual mate choice in Pundamilia (O. Svensson, personal communication). To test whether females prefer one type of male, the proportion of female positive responses to each male within trials was compared with WSR tests. The female preference for the red (conspecific) male was calculated as the proportion of positive female responses to the red male $(R)$ minus that to the blue male $(B)$, divided by the sum of the proportion of positive female responses to both males, i.e. $(R-B) /(R+B)$. The denominator corrects for the absolute proportion of positive female responses. We compared female preference for the conspecific male between the three treatments with a Kruskal-Wallis test. Post hoc testing between treatments was done with Mann-Whitney $U$ (MWU) tests.

The data in the text are presented as medians with the inter-quartile range (25th-75th percentile). Analyses were carried out with SPSS 12.0.1. All quoted probabilities are for two-tailed tests of significance.

\section{Results}

Same-tube treatment

Red females had a significant preference for the red male: The proportion of positive female responses was significantly higher to red than to blue males (Fig. 2; Table 1).

During the test period, the frequency of courtship display by red males was $0.10 / \mathrm{min}(0.04-0.27)$ and by blue males $0.15 / \min (0.05-0.27)$. This was not significantly different (WSR test: $Z=-0.157, P=0.875, N=14$ ).

Red-large-tube and blue-large-tube treatment

In the red-large-tube treatment, red females had a significant preference for the red male. In the blue-large-tube treatment, this preference was reversed to a non-significant preference for the blue male (Fig. 2; Table 1).

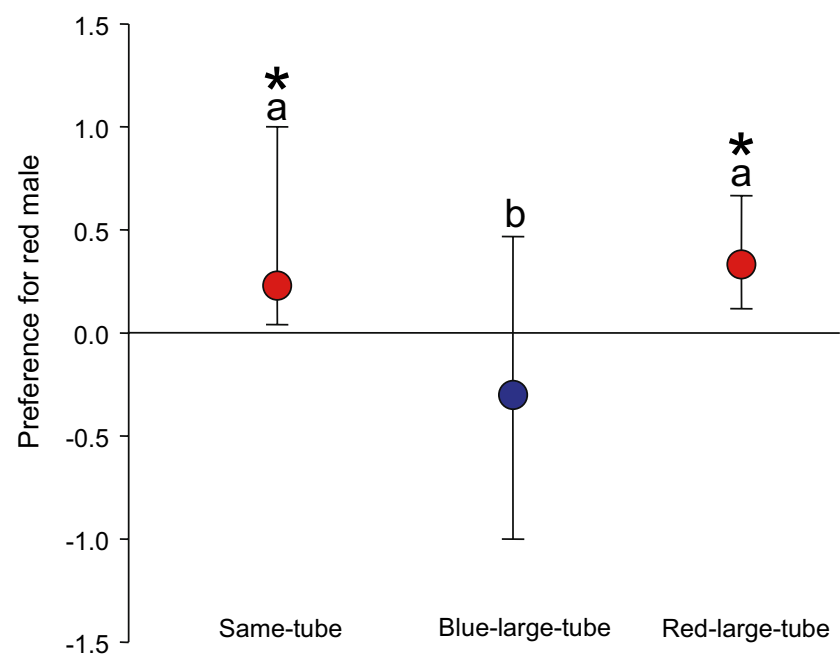

Fig. 2 The preference of red females for red (conspecific) males (median and inter-quartile range), calculated as proportion of positive female response to the red male minus that to the blue male, divided by the sum of the proportion of positive female response to both males. The $x$-axis indicates the no-preference line. Significant preference, tested by comparing the proportion of positive female response to the red and blue males, respectively, is indicated above the data points with an asterisk, $P<0.05$ (WSR tests, all $N=14$, see Table 1). Comparisons between same-tube (both males with small tubes), blue-large-tube and red-large-tube treatments are indicated by letters (MWU tests): Data points with different letters are significantly different from each other, $P<0.05$

The frequency of male display did not differ between red and blue males in either the red-large-tube or the blue-largetube treatment (blue-large-tube treatment: red males 0.08 / min [0.06-0.16], blue males $0.08 / \min [0.06-0.14]$, WSR test: $Z=-1.099, P=0.272, N=14$; red-large-tube treatment: red males $0.07 / \mathrm{min}[0.03-0.11]$, blue males $0.11 / \mathrm{min}[0.05$ $0.16]$, WSR test: $Z=-1.350, P=0.177, N=14)$. The female preference for males with the large tube can therefore not be attributed to differences in courtship effort.

Table 1 Proportion of positive female responses, calculated as the number of times a male courtship display was followed by a female approach, divided by the total number of male courtship displays

\begin{tabular}{lllll}
\hline Treatment & Red male & Blue male & \multicolumn{2}{l}{ WSR test } \\
\cline { 3 - 5 } & & & $Z$ & $P$ \\
\hline $\begin{array}{c}\text { Same-tube } \\
(N=14)\end{array}$ & $0.22(0.16-0.34)$ & $0.16(0.00-0.20)$ & -2.919 & 0.004 \\
$\begin{array}{c}\text { Blue-large-tube } \\
(N=14)\end{array}$ & $0.07(0-0.18)$ & $0.10(0.07-0.20)$ & -0.785 & 0.433 \\
$\begin{array}{c}\text { Red-large-tube } \\
(N=14)\end{array}$ & $0.19(0.13-0.24)$ & $0.09(0.05-0.15)$ & -2.354 & 0.019 \\
\end{tabular}

Values shown are the median and, in parentheses, the 25th and 75 th percentiles, of the proportion of positive female responses to the red and the blue stimulus males. Sample sizes, $Z$ values and significance (WSR tests) are indicated. 


\section{Comparison between treatments}

We tested the prediction that the preference of red females for the red (conspecific) male is reduced by the presence of a larger tube in the territory of the blue (heterospecific) male. This prediction was supported. The female preference for the red male was different between treatments (Kruskal-Wallis test: $\left.\chi^{2}=7.39, d f=2, P=0.025\right)$, due to a reduced preference for the red male in the blue-large-tube treatment: The female preference for the red male was significantly lower in the blue-large-tube treatment compared to the red-largetube treatment (Fig. 2, MWU test: $U=49, P=0.024, N_{1}=14$, $N_{2}=14$ ) as well as compared to the same-tube treatment (Fig. 2, MWU test: $U=46, P=0.016, N_{1}=14, N_{2}=14$ ). This indicates that female preference for males with larger tubes can override that for males of their own colour.

The mean of the preference for red males was higher in the red-large-tube treatment than in the same-tube treatment. However, this difference was not significant (Fig. 2, MWU test: $U=89, P=0.70, N_{1}=14, N_{2}=14$ ).

The frequency of male display did not differ between treatments for red males (MWU test: same-tube versus redlarge-tube treatment, $U=92, P=0.76, N_{1}=14, N_{2}=14$; sametube versus blue-large-tube treatment, $U=95, \mathrm{P}=0.89, N_{1}=14$, $N_{2}=14$ ) or for blue males (MWU test: same-tube versus bluelarge-tube treatment, $U=98, P=0.98, N_{1}=14, N_{2}=14$; sametube versus red-large-tube treatment, $U=93, P=0.82, N_{1}=14$, $\left.N_{2}=14\right)$.

\section{General discussion}

The question addressed here is whether territory quality influences mate choice and can override the female preference for conspecific male nuptial coloration. The results are consistent with our expectations. We first confirmed that the alpha male prefers a large tube over a small one, showing that males are sensitive to cues of territory quality (experiment I). Alpha males performed more courtship displays in the vicinity of a large tube than a small one and preferentially charged rival males from the zone with the large tube. One could argue that this largetube preference was mediated by female behaviour in case females prefer large tubes (see mate choice experiments). Nevertheless, irrespective of how the male preference comes about, the data show that territory quality matters in the reproductive decisions of this species. In subsequent mate-choice experiments, we showed that red females prefer males of their own species in the absence of differences in territory quality (experiment II). This confirms earlier results (Seehausen and Van Alphen 1998; Haesler and Seehausen 2005). This preference changed significantly into the direction of blue (heterospecific) males when those males had a larger tube, resulting in a non-significant preference for blue. Furthermore, female preference for red (conspecific) males was significantly lower in the blue-large-tube treatment than in the red-largetube treatment. Thus, differences in tube size can alter and override the female preference for red (conspecific) males.

Multiple cues for mate choice may reinforce one another (Candolin 2003). Indeed, the preference for red males was slightly higher in the red-large-tube treatment than in the same-tube treatment. However, this difference was nonsignificant, suggesting no strong additive effect of preference for males with own colour and males with large tubes.

It seems unlikely that the female preference for the male with the larger tube was mediated by an effect on the male's courtship activity. Males readily accepted both types of artificial crevices as the focal point of their territory. In addition, vertical coloration bars, which are a strong indication of territoriality (Baerends and Baerends-Van Roon 1950; Maan et al. 2004), were in all cases maximally expressed in both stimulus males. Furthermore, although male courtship effort may influence female preference (Haesler and Seehausen 2005), we could not detect a difference in this effort associated with the size of the tubes.

Rock-dwelling cichlids form lek aggregations where multiple males occupy individual territories over rocky or sandy sites (Seehausen 1996; Maan et al. 2004). The size of their territories, as well as the size and number of rocky structures contained in them, can vary among territorial males. In our experiment, we mimicked variation in crevice size by providing large and small PVC tubes. Why do females find males occupying large tubes, or a high-quality territory, more attractive? First, females may gain indirect benefits by mating with a male with a high-quality territory, because owning such a territory may honestly signal superior genetic or phenotypic quality (Zahavi 1975; Cox and Le Boeuf 1977; Andersson 1994; Berglund et al. 1996; Wong and Candolin 2005). Such a 'good-genes' scenario is especially likely in taxa without paternal care, such as most haplochromine species. Several studies have indicated that dominance is related to heritable fitness (Moore 1990; Alatalo et al. 1991; but see Qvarnström and Forsgren 1998). Second, there are potential direct benefits from choosing a large crevice, as it may provide better shelter during the courtship and spawning event (Kellog et al. 2000; Svensson and Kvarnemo 2003).

Our study is interesting for biologists trying to understand the evolution of mate choice criteria in situations where heterospecifics possess traits that resemble highquality conspecifics (Pfennig 1998; Hankinson and Morris 2003; Wymann and Whiting 2003). Species recognition cues, such as colour, may be in conflict with mate-quality cues, such as large body size or territory size. In such a situation, species recognition may be hampered. How such 
conflicts are resolved depends on the cost of mating with heterospecific (Pfennig 1998; Wymann and Whiting 2003). Heterospecific matings are likely to be more costly among reproductively isolated species than among hybridising incipient species. This is because both pre- and postzygotic isolation are believed to intensify with divergence (time) between taxa (Coyne and Orr 1997), making hybrid matings more costly between reproductively isolated species either as a result of reduced mating success and/or lower viability. It would be interesting to test whether the conflict between species recognition cue and territory quality is dependent on the degree of reproductive isolation between red and blue Pundamilia fish.

The findings are relevant for situations in which females are faced with heterospecific males that are capable of maintaining better-quality territories. Our study is also relevant for the recent proposed theory that male competition for mating territories can facilitate sympatric speciation by sexual selection (e.g. Seehausen and Schluter 2004; Dijkstra et al. 2005). Recent theoretical investigations indicate that sympatric speciation by sexual selection requires unrealistically stringent conditions (Arnegard and Kondrashov 2004; Kirkpatrick and Nuismer 2004; Van Doorn et al. 2004). In particular, it is unclear how a novel male phenotype can invade without frequency-dependent natural selection. The stable coexistence of incipient species is likewise problematic. Van Doorn et al. (2004), Seehausen and Schluter (2004) and Mikami et al. (2004) independently proposed that male-male competition for mating territories could generate this frequency-dependent selection on male nuptial coloration. Rare males would have an advantage if males bias aggression towards phenotypically similar rivals. Such an aggression bias has been found in red and blue Pundamilia (Dijkstra 2006); field evidence is also consistent with negative frequency-dependent selection through male competition (Mikami et al. 2004; Seehausen and Schluter 2004). An aggression bias would facilitate the invasion of novel colour types, as well as stabilise coexistence of incipient species. However, this proposed advantage for rare male colour types in male competition depends on the premise that it translates into a higher reproductive success despite the fact that females have a preference for mates with their own colour (Seehausen and Van Alphen 1998). The present study shows that territory quality can override female preference for male colour, consistent with this important premise.

Traditionally, the explosive speciation of Lake Victoria cichlid fish has been explained by sexual selection exerted by female mate choice for male nuptial coloration (Seehausen et al. 1999; Kocher 2004). Our findings indicate that not only male coloration is important in sexual selection, but also a male's territory.
Acknowledgements We thank Marcel Buczkiewicz, Sander van Dijk, Tim Fieret and Barbara Verwayen for developing the first pilot studies that eventually led to this manuscript. We are indebted to Mhoja Kayeba, Mohamed Haluna, John Mrosso and Martine Maan for fish collection. Machteld Verzijden, Inke van der Sluijs, Martine Maan and Ole Seehausen are greatly acknowledged for their advice on the mate-choice experiments and comments on the manuscript; Charlotte Hemelrijk helped us with the dominance experiment. Anne Vos and Marcel Buczkiewicz are acknowledged for help with the dominance experiment. Serge Daan, Nikolaus von Engelhardt, Bernd Riedstra, Jerry Hogan, Tim Fawcett and one anonymous reviewer gave valuable comments on the manuscript. The research was financed by the Netherlands Organisation for Scientific Research, NWO (SLW) grant 810.64.013. All experiments were carried out under licence (DEC D4335A and 2812) from Groningen University and complied with current laws in The Netherlands.

\section{References}

Alatalo RV, Lundberg A, Glynn C (1986) Female pied flycatchers choose territory quality and not male characteristics. Nature 323:152-153

Alatalo RV, Höglund J, Lundberg A (1991) Lekking in the black grouse - a test of male viability. Nature 352:155-156

Andersson M (1994) Sexual selection. Princeton Univ. Press, Princeton

Arnegard ME, Kondrashov AS (2004) Sympatric speciation by sexual selection is unlikely. Evolution 58:222-237

Baerends GP, Baerends-Van Roon JM (1950) An introduction to the study of the ethology of cichlid fishes. Behav Suppl 1:233-366

Berglund A, Bisazza A, Pilastro A (1996) Armaments and ornaments: an evolutionary explanation of traits of dual utility. Biol J Linn Soc 58:385-399

Candolin U (2003) The use of multiple cues in mate choice. Biol Rev 78:575-595

Cox CR, Le Boeuf BJ (1977) Female incitation of male competition: a mechanism in sexual selection. Am Nat 111:317-335

Coyne JA, Orr HA (1997) Patterns of speciation in Drosophila revisited. Evolution 51:295-303

Dijkstra PD (2006) Know thine enemy. Intrasexual selection and sympatric speciation in Lake Victoria cichlid fish. $\mathrm{PhD}$ thesis, University of Groningen

Dijkstra PD, Seehausen O, Groothuis TGG (2005) Direct male-male competition can facilitate invasion of new colour types in Lake Victoria cichlids. Behav Ecol Sociobiol 58:136-143

Dijkstra PD, Seehausen O, Gricar BLA, Maan ME, Groothuis TGG (2006) Can male-male competition stabilize speciation? A test in Lake Victoria cichlids. Behav Ecol Sociobiol 59:704-713

Dijkstra PD, Hekman R, Schulz RW, Groothuis TGG (2007a) Social stimulation, nuptial coloration, androgens, and immunocompetence in a sexual dimorphic cichlid fish. Behav Ecol Sociobiol 61:599-609

Dijkstra PD, Seehausen O, Pierotti MER, Groothuis TGG (2007b) Male-male competition and speciation: aggression bias towards differently coloured rivals varies between stages of speciation in a Lake Victoria cichlid species complex. J Evol Biol 20: 496-502

Dominey WJ (1984) Effects of sexual selection and life history on speciation: species flocks in African cichlids and Hawaiian Drosophila. In: Echelle AA, Kornfield I (eds) Evolution of fish species flocks. University of Maine Press, Orono, pp 231-249

Haesler MP, Seehausen O (2005) Inheritance of female mating preference in a sympatric sibling species pair of Lake Victoria 
cichlids: implications for speciation. Proc R Soc Lond B 272:237-245

Hankison SJ, Morris MR (2003) Avoiding a compromise between sexual selection and species recognition: female swordtail fish assess multiple species-specific cues. Behav Ecol 14(2):282-287

Hemelrijk CK, Wantia J, Gygax L (2005) The construction of dominance order: comparing performance of five methods using an individual-based model. Behaviour 142:1043-1064

Höglund J, Alatalo RV (1995) Leks. Princeton Univ. Press, Princeton

Johnson TC, Scholz CA, Talbot MR, Kelts K, Ricketts RD, Ngobi G, Beuning K, Ssemmanda I, McGill JW (1996) Late Pleistocene desiccation of Lake Victoria and rapid evolution of cichlid fishes. Science 273:1091-1093

Kellog KA, Stauffer JR Jr, McKaye KR (2000) Characteristics that influence male reproductive success on a lek of Lethrinops c.f. parvidens (Teleostei: Cichlidae). Behav Ecol Sociobiol 47:164-170

Kirkpatrick M, Nuismer S (2004) Sexual selection can constrain sympatric speciation. Proc R Soc Lond B 271:687-693

Kocher TD (2004) Adaptive evolution and explosive speciation: the cichlid fish model. Nat Genet 5:289-298

Kodric BA, Johnson SC (2002) Ultraviolet reflectance patterns of male guppies enhance their attractiveness to females. Anim Behav 63:391-396

Maan ME, Seehausen O, Soderberg L, Johnson L, Ripmeester AP, Mrosso HDJ, Taylor MI, van Dooren TJM, van Alphen JJM (2004) Intraspecific sexual selection on a speciation trait, male coloration, in the Lake Victoria cichlid Pundamilia nyererei. Proc R Soc Lond B 271:2445-2452

McElroy DM, Kornfield I (1990) Sexual selection, reproductive behavior, and speciation in the mbuna species flock of Lake Myasa (Pisces: Cichlidae). Environ Biol Fishes 28:273-284

McKaye KR (1991) Sexual selection and the evolution of the cichlid fishes of Lake Malawi, Africa. In: Keenleyside MHA (Ed) Cichlid fishes: behaviour, ecology, and evolution. Chapman and Hall, New York, pp 241-257

McKaye KR, Svata ML, Stauffer JR Jr (1990) Bower size and male reproductive success in a cichlid fish lek. Am Nat 135:597-613

Mikami OK, Kohda M, Kawata M (2004) A new hypothesis for species co-existence: male-male repulsion promotes co-existence of competing species. Pop Ecol 46:213-217

Moore AJ (1990) The inheritance of social dominance, mating behaviour and attractiveness to mates in Nauphoeta cinerea. Anim Behav 39:388-397

Parker A, Kornfield I (1996) Polygynandry in Pseudotropheus zebra, a cichlid fish from Lake Malawi. Environ Biol Fishes 47:345-352

Pauers MJ, McKinnon JS, Ehlinger TJ (2004) Directional sexual selection on chroma and within-pattern colour contrast in Labeotropheus fuelleborni. Biology Letters 271:S444-S447

Pfennig KS (1998) The evolution of mate choice and the potential for conflict between species and mate-quality recognition. Proc $\mathrm{R}$ Soc Lond B 265:1743-1748

Qvarnström A, Forsgren E (1998) Should females prefer dominant males? Trends Ecol Evol 13(12):498-501
Seehausen O (1996) Lake Victoria rock cichlids: taxonomy, ecology and distribution. Verduyn Cichlids, Zevenhuizen, $304 \mathrm{p}$

Seehausen O (1997) Distribution of and reproductive isolation among color morphs of a rock-dwelling Lake Victoria cichlid (Haplochromis nyererei). Ecol Freshwater Fish 6:59-66

Seehausen O (2006) African cichlid fish: a model system in adaptive radiation research. Proc R Soc Lond B 273:1987-1998

Seehausen O, Schluter D (2004) Male-male competition and nuptial color displacement as a diversifying force in Lake Victoria cichlid fish. Proc R Soc Lond B 271:1345-1353

Seehausen O, van Alphen JJM (1998) The effect of male coloration on female mate choice in closely related Lake Victoria cichlids (Haplochromis nyererei complex). Behav Ecol Sociobiol 42:1-8

Seehausen O, van Alphen JJM (1999) Can sympatric speciation by disruptive sexual selection explain rapid evolution of cichlid diversity in Lake Victoria? Ecol Lett 2:262-271

Seehausen O, van Alphen JJM, Witte F (1997) Cichlid fish diversity threatened by eutrophication that curbs sexual selection. Science 277:1808-1811

Seehausen O, Lippitsch E, Bouton N, Zwennes H (1998) Mbipi, the rock-dwelling cichlids of Lake Victoria: description of three new genera and fifteen new species (Teleostei). Ichthyol Explor Freshw 9:129-228

Seehausen O, van Alphen JJM, Lande R (1999) Color polymorphism and sex ratio distortion in a cichlid fish as an incipient stage in sympatric speciation by sexual selection. Ecol Lett 2:367-378

Seehausen O, Koetsier E, Schneider MV, Chapman LJ, Chapman CA, Knight ME, Turner GF, van Alphen JJM, Bills R (2003) Nuclear markers reveal unexpected genetic variation and a CongoleseNilotic origin of the Lake Victoria cichlid species flock. Proc R Soc Lond B 270:129-137

Smith PF, Kornfield I (2002) Phylogeography of Lake Malawi cichlids of the genus Pseudotropheus: significance of allopatric colour variation. Proc R Soc Lond B 269:2495-2502

Svensson O, Kvarnemo C (2003) Sexually selected nest-buildingPomatoschistus minutus - males build smaller nest-openings in the presence of sneaker males. J Evol Biol 16:896-902

Taylor MI, Turner GF, Robinson RL, Stauffer JR Jr (1998) Sexual selection, parasites and bower height skew in a bower-building cichlid fish. Anim Behav 56:379-384

van Doorn GS, Diekmann U, Weissing FJ (2004) Sympatric speciation by sexual selection: a critical re-evaluation. Am Nat 163:709-725

Witte-Maas E, Witte F (1985) Haplochromis nyererei, a new cichlid fish from Lake Victoria named in honour of Mwalimu Julius Nyerere, President of Tanzania. Leiden, Brill

Wong BBM, Candolin U (2005) How is female mate choice affected by male competition? Biol Rev 80:559-571

Wymann MN, Whiting MJ (2003) Male mate preference for large size overrides species recognition in allopatric flat lizards (Platysaurus broadleyi). Acta Ethol 6:19-22

Zahavi A (1975) Mate selection: a selection or a handicap. J Theor Biol 53:205-214 